\title{
The Implementation of Therapeutic Alliance in the Rehabilitation of an Elite Pediatric Athlete with Salter-Harris Fracture: A Case Report
}

Lucas VanEtten, DPT, OCS1', Matthew Briggs, PhD, DPT, SCS, AT², John DeWitt, DPT, SCS, AT'1, Cody Mansfield, DPT, OCS, AT, FAAOMPT ${ }^{3}$ a , Christopher Kaeding, MD ${ }^{4}$

1 OSU Sports Medicine, The Ohio State University Wexner Medical Center, Columbus, OH, USA, 2 OSU Sports Medicine, The Ohio State University
Wexner Medical Center, Columbus, OH, USA; Sports Medicine Research Institute, The Ohio State University Wexner Medical Center, Columbus, OH,
USA; Department of Orthopaedics, The Ohio State University Wexner Medical Center, Columbus, OH, USA; School of Health and Rehabilitation
Sciences, College of Medicine, The Ohio State University, Columbus, OH, USA, 3 OSU Sports Medicine, The Ohio State University Wexner Medical
Center, Columbus, OH, USA; School of Health and Rehabilitation Sciences, College of Medicine, The Ohio State University, Columbus, OH, USA, 4 OSU
Sports Medicine, The Ohio State University Wexner Medical Center, Columbus, OH, USA; Sports Medicine Research Institute, The Ohio State University
Wexner Medical Center, Columbus, OH, USA; Department of Orthopaedics, The Ohio State University Wexner Medical Center, Columbus, OH, USA
Keywords: salter-harris fracture, physical therapy, movement system, boat racing
https://doi.org/10.26603/001c.19448

\section{International Journal of Sports Physical Therapy}

Vol. 16, Issue 2, 2021

\begin{abstract}
Background/Purpose
Although research on the value of therapeutic alliance is prominent in other areas of health care, physical therapy research is limited. The purpose is to describe the incorporation of therapeutic alliance concepts throughout the rehabilitation of an elite pediatric athlete with a complicated recovery following a fracture to the distal femoral epiphysis.
\end{abstract}

\section{Case Description}

A 14-year-old male was referred to physical therapy following an open reduction and internal fixation to address a type IV Salter-Harris fracture of the right distal femoral epiphysis. Post-operative care included immobilization in a brace for six weeks and he initiated physical therapy for four weeks (post-op weeks 6-10). At 10-weeks post-injury his range of motion and strength were severely limited compared to expected post-operative milestones. Due to these deficits an arthroscopic debridement of the subject's right knee, hardware removal, and manipulation under anesthesia was performed. The subject then reported to the physical therapist on post-operative day three for evaluation and treatment without bracing or weight-bearing restrictions.

\section{Outcomes}

The episode of care spanned 17 weeks and included 25 physical therapy sessions. To facilitate therapeutic alliance with the subject, clear communication and easily measurable goals were established and connected to the subject's relevant needs as an athlete. The plan of care was divided into three phases using "chunking” techniques to establish the rehabilitation priorities. The subject demonstrated improved range of motion, strength and was able to return to hydroplane racing and won a national championship in his age group.

\section{Discussion}

The unique aspect of this case was the incorporation of therapeutic alliance concepts and techniques into the rehabilitative management of a subject with a complicated fracture to

\footnotetext{
a Corresponding author:

Cody J. Mansfield

OSU Sports Med Gahanna

920 North Hamilton Rd, Suite 600, Gahanna, OH, 43230

Office: (614) 293-7600; Fax: 614-293-7540

Cody.mansfield@osumc.edu
} 
the distal femoral epiphysis. The physical therapist built trust with the subject and facilitated a successful return to elite hydroplane boat racing.

\section{Level of Evidence}

4

\section{Study Design}

Case Report

\section{INTRODUCTION}

Developing a therapeutic alliance with subjects and their social support systems is paramount, especially when rehabilitating from injuries with limited existing knowledge on normative values for recovery. ${ }^{1,2}$ Often utilized in clinical psychology, therapeutic alliance is the combination of an emotional bond between the subject and clinician and involves a mutual agreement pertaining to the plan of care. ${ }^{3,4}$ Therapeutic alliance exists in situations when there is subject-therapist agreement on goals and an affective bond exists between the subject and the therapist..$^{5}$ Although many definitions exist, several characteristics, including flexibility in treatment design, honesty regarding progress, attending to subject experience and admission of insecurity or being unsure how to proceed, have been shown to enhance rapport and therapeutic alliance. ${ }^{2,6}$

Eight dimensions have been identified across which therapeutic alliance is built in physical therapy (Table 1) ${ }^{7}$ Aspects of therapeutic alliance are emphasized when the physical therapist engages in shared decision making with their subjects. ${ }^{8}$ When physical therapists are successful in implementing therapeutic alliance and shared decision making these factors can improve subject adherence, subject satisfaction, and subject quality of life in healthcare settings. ${ }^{7}$ Utilizing this approach can help physical therapists individualize subject care, account for biopsychosocial factors, and facilitate conflict resolution. ${ }^{8}$

In physical therapy, behavioral change is a key aspect to long term success with musculoskeletal conditions and should be addressed throughout the plan of care. Establishing a relationship with the subject where the subject feels "seen, heard, and believed" could enhance care and improve subject outcomes. ${ }^{9-11}$ This is important for all subject cases that physical therapists evaluate and treat, but can be beneficial when a subject is being seen for a condition where scientific evidence to inform the treatment approach is not substantial. One example of a condition with limited research to guide clinical decision making related to rehabilitation is a complicated fracture to the distal femoral epiphysis. These fractures account for approximately $7 \%$ of lower extremity fractures and up to $6 \%$ of all physeal fractures. ${ }^{12-14}$ Fractures to the distal femoral epiphysis can be difficult to manage and may result in severe complications such as poor healing, growth arrest (27.4\% to 62\%), loss of range of motion (4\% to $24 \%$ ), and these complications can result in substantial loss of function. ${ }^{12-14}$ of all the long bones in the body, fractures to the distal femoral epiphysis are important to manage, because it is responsible for $35 \%$ of the total leg length attained through adolescents. ${ }^{12}$ Limited literature exists to assist and guide postoperative physical therapy decisions and management of

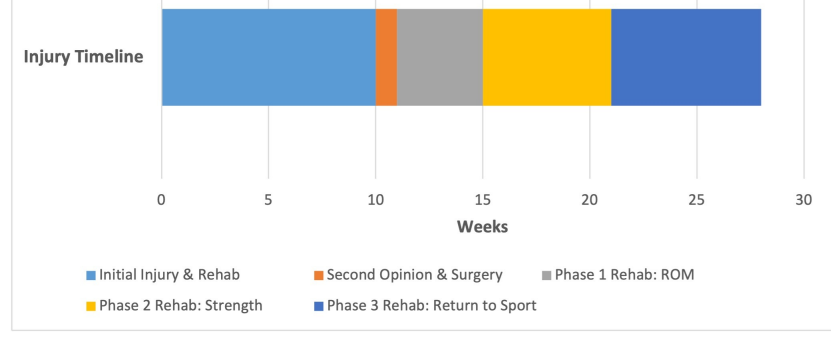

\section{Figure 1: Timeline of Rehabilitation Stages}

Figure 1 details the entire course of care for this patient from initial injury all the way to return to sport.

femoral growth plate fractures. ${ }^{12-14}$ When the scientific evidence demonstrates the severity of the condition, but offers little guidance in post-operative rehabilitation, building rapport and therapeutic alliance is crucial for shared decision making.

The purpose of this case report was to describe the incorporation of therapeutic alliance concepts and techniques throughout the rehabilitation of an elite pediatric athlete with a complicated recovery following a fracture to the distal femoral epiphysis. Each of the eight described therapeutic alliance behaviors are defined with examples from this clinical case that demonstrate each characteristic. The importance of subject involvement in decision making and the development of therapeutic alliance across the episode of care were central to successfully rehabilitating the athlete with a return to full sport participation. Particular emphasis in this case study was placed on decision making related to appropriate rehabilitation progression, methods for maintaining subject engagement across an extended timeline, and specialized interventions to assist in return to competitive sports. The subject of this case report gave assent and parents provided permission for their case to be shared.

\section{DESCRIPTION OF CASE}

A 14-year-old, Caucasian male was referred to physical therapy after a complicated recovery following an open reduction and internal fixation of the distal femoral epiphysis (Figure 1). Prior to his injury, he was an active lacrosse player and nationally prominent hydroplane boat racer (Table 2). Additionally, he was recreationally active in a variety of other sports, such as handball and lacrosse. He had no previous significant injuries and his medical history was unremarkable.

The subject initially sustained a type IV Salter-Harris 
Table 1: Therapeutic Alliance and Shared Decision Making in Physical Therapy

\begin{tabular}{|c|c|c|c|}
\hline \multicolumn{2}{|r|}{ Therapeutic Alliance } & \multicolumn{2}{|r|}{ Shared Decision Making } \\
\hline Dimensions & Details & Stages & Details \\
\hline 1 & $\begin{array}{l}\text { Congruence in goals: Characterized by } \\
\text { having similar expectations between } \\
\text { therapist and subject. }\end{array}$ & \multirow{3}{*}{1} & \multirow{3}{*}{$\begin{array}{l}\text { Prepare for Collaboration: The physical therapist } \\
\text { should facilitate subject involvement to determine } \\
\text { decisions for plan of care and priorities of both the } \\
\text { subject and physical therapist. }\end{array}$} \\
\hline 2 & $\begin{array}{l}\text { Connectedness and friendliness of the } \\
\text { physical therapist: Characterized by } \\
\text { kindness and engaging the subject. }\end{array}$ & & \\
\hline 3 & $\begin{array}{l}\text { Communication style: including non- } \\
\text { verbal body language and clarifying of } \\
\text { information presented. }\end{array}$ & & \\
\hline 4 & $\begin{array}{l}\text { Clear Expectations for the process: } \\
\text { Clarity in goal setting for overall care } \\
\text { and within sessions. }\end{array}$ & \multirow{3}{*}{2} & \multirow[t]{3}{*}{$\begin{array}{l}\text { Exchange Information: The physical therapist should } \\
\text { determine the subject values and discuss the benefits } \\
\text { and risks of different treatment options. }\end{array}$} \\
\hline 5 & $\begin{array}{l}\text { Influencing factors: Addressing } \\
\text { environment, physical therapist } \\
\text { reputation, and subject life experiences. }\end{array}$ & & \\
\hline 6 & $\begin{array}{l}\text { Individualized Treatment: Care specific } \\
\text { and responsive to the subject. }\end{array}$ & & \\
\hline 7 & $\begin{array}{l}\text { Partnership in decision making: Having } \\
\text { the subject participate in decisions with } \\
\text { physical therapist. }\end{array}$ & \multirow[b]{2}{*}{3} & \multirow[t]{2}{*}{$\begin{array}{l}\text { Affirm and Implement Decision: The plan of care is } \\
\text { agreed upon by physical therapist and subject, and the } \\
\text { priorities of both are reaffirmed. }\end{array}$} \\
\hline 8 & $\begin{array}{l}\text { Establishing roles and responsibilities: } \\
\text { Determine roles of subject and physical } \\
\text { therapist including accountability for } \\
\text { those responsibilities. }\end{array}$ & & \\
\hline
\end{tabular}

Table 2: Demands of Hydroplane Racing

\begin{tabular}{|c|c|}
\hline $\begin{array}{l}\text { Description } \\
\text { of Sport }\end{array}$ & $\begin{array}{l}\text { - Hydroplane racing involves riding small, motored boats across a lake along courses and in straight lines for speed. } \\
\text { - Participants kneel in a crouched position behind the steering wheel and utilize their lower extremities to absorb } \\
\text { - Various classes exist, including technical classes that emphasize change of direction and controlled maneuvering, as } \\
\text { well as straight line racing. } \\
\text { - Racers attain speeds of up to } 50 \mathrm{MPH} \text { while racing. }\end{array}$ \\
\hline Shoulder & $\begin{array}{l}\text { - Active shoulder flexion range of motion of } 160^{\circ} \text { is preferred. } \\
\text { - Sustained pressure needs to be maintained on steering wheel therefore adequate shoulder and upper arm strength is } \\
\text { required. }\end{array}$ \\
\hline $\begin{array}{l}\text { Trunk } \\
\text { Stabilizers }\end{array}$ & $\begin{array}{l}\text { - Adequate trunk stabilizer strength is a key component to maintaining balance while utilizing arms to stabilize the } \\
\text { boat and legs to control for unpredictable changes from the boat. }\end{array}$ \\
\hline Hip & $\begin{array}{l}\text { - Need to be able to maintain crouch position with hips approximately in line with knees in the sagittal plane. (Hip flex- } \\
\text { ion }>125^{\circ} \text {, knee flexion }>130^{\circ} \text { pending limb girth) } \\
\text { - Minimum of } 5 / 5 \text { hip strength in all directions with manual muscle testing. }\end{array}$ \\
\hline Knee & $\begin{array}{l}\text { - In order to assume proper crouch position in boat, a minimum of } 130^{\circ} \text { of knee flexion is required. } \\
\text { - Quadriceps strength is extremely important to maintain proper position. }\end{array}$ \\
\hline Foot/Ankle & - Full closed chain dorsiflexion is required to maximize success. \\
\hline Balance & $\begin{array}{l}\text { - Racers are commonly barefoot or wear minimalist shoe apparel and need to be able to balance on a boat changing di- } \\
\text { rection and adjust various wakes in the water. }\end{array}$ \\
\hline
\end{tabular}

MPH: miles per hour

fracture of the right distal femoral epiphysis while playing handball. A type IV Salter-Harris fracture is suggestive of a fracture compromising the epiphyseal plate, metaphysis, and epiphysis. The mechanism of injury occurred when he was running laterally, and in order to dodge a ball, he changed direction and twisted backwards over his leg while his foot stayed in place due to traction of his shoe. As he hit the ground he "heard a pop." He was evaluated by an orthopedic surgeon immediately following the injury and underwent surgical repair with pin fixation of the fracture 
within 24 hours of the initial injury (Figure 1). Post-operative care included immobilization in a brace for six weeks following surgery, and he initiated physical therapy at another facility for four weeks (post-operative weeks 6-10). At 10 weeks post-injury his family reported severely limited range of motion, poor gait mechanics, and limited strength, prompting a second opinion from another orthopedic surgeon. Based on follow-up imaging and clinical consultation, the decision was made to proceed with an arthroscopic debridement of the subject's right knee, hardware removal, and manipulation under anesthesia. Surgery was successful at normalizing range of motion of the knee. While under anesthesia, the surgeon noted $0^{\circ}$ degrees of extension and $120^{\circ}$ flexion range of motion. The subject then reported to physical therapy on post-operative day three for evaluation and treatment without bracing.

\section{EXAMINATION AND EVALUATION (TABLE 3)}

The subject reported to physical therapy using a single axillary crutch in the opposite upper extremity for ambulation with post-operative instructions of weight-bearing as tolerated. He demonstrated decreased range of motion, swelling and poor quadriceps activation as measured by quadriceps lag on straight leg raise that would be considered normal for his overall episode of care and post-operative state $\left(15^{\circ} \mathrm{ex}-\right.$ tensor lag with straight leg raises). ${ }^{15-18}$ The subject ambulated with a limp, and visual assessment by physical therapist suggested decreased stance time on the right foot and lack of terminal knee extension due to knee stiffness, and was limited to approximately a $20^{\circ}$ knee extension deficit at mid-stance and inability to fully weight shift onto the right lower extremity. ${ }^{16,19-21}$ No signs of infection or neurovascular compromise were present, and all incisions were clean, dry, and appropriately dressed with sutures intact. $^{22-25}$ Marked reduction in soft tissue mobility of the quadriceps and hamstring was noted with palpation as perceived by physical therapist and subject, as well as patellar hypomobility with less than one quadrant of mobility in all planes of movement. Bruising was minimal at time of evaluation, and effusion of the knee joint was measured at a $2+$ using the sweep test. ${ }^{26}$

\section{SUBJECT’S GOALS}

After discussion with the subject and his parents, the subject's primary goal of physical therapy was full return to competitive hydroplane racing at the elite level (Table 2). The subject was a competitive lacrosse player, and an elite hydroplane athlete (placed third nationally in his age group the previous year). The subject and his father briefly described hydroplane racing, and the physical therapist observed several videos of the subject in previous competitions. The demands of the sport were appraised by the treating physical therapist (Table 2).

\section{THREATS AND OPPORTUNITIES FOR THERAPEUTIC ALLIANCE}

This case presented several challenges to developing therapeutic alliance with the subject and parents. The subject's previous experience with physical therapy was suboptimal and he yielded a poor outcome from the surgery, which created an environment where distrust in the rehabilitation process was understandable. His parents and the subject had concerns about him undergoing two substantial knee surgeries at such a young age. This also detracted from therapeutic alliance, and could impact care by decreasing compliance with treatment recommendations. Treating a subject in adolescents presents unique challenges compared to treating adults, because there are several interactions to consider with the therapeutic alliance and shared decision making: the subject with the physical therapist, the subject and parents, and the physical therapist and parents. However, in such a case where many factors would challenge the subject-parent-physical therapist interaction, strategies can be used to emphasize and build therapeutic alliance. ${ }^{4,6-8,11}$ This was accomplished in the evaluation through clear communication and emphasized in the creation of the plan of care for his episode. Goals were based on objective measures (Table 3), demands of hydroplane boat racing (Table 2), and phases of post-operative rehabilitation (Table 4). The subject's progress in each phase was assessed in several ways. Gait was appraised visually by the physical therapist, return to functional exercise and sport related tasks was self-report, and objective measures of strength, range of motion and swelling assessment were taken with goniometer, sweep test, manual muscle testing, isokinetic and isometric strength testing with electromechanical dynamometer (Biodex System III Dynamometer, Biodex Medical Systems, Shirley, NY), and one repetition maximum testing on gym equipment such as leg press and knee extension machines. ${ }^{27-33}$

\section{DEVELOPMENT OF THE PLAN OF CARE}

\section{PLAN OF CARE DEVELOPMENT}

To facilitate a therapeutic alliance with the subject, the physical therapist determined that clear communication and objective, easily measurable goals would be most beneficial to maintain the focus of the subject and his family in their efforts. The subject and his father expressed anxiety about the many complications and limitations, and both were unsure how to begin the rehabilitation process. The subject seemed unsure of rehabilitation and the pain he felt with movement, and was reported to be at risk of non-compliance by his father, particularly if he could not return to sports that he found meaningful (e.g. hydroplane racing and lacrosse). In order to help manage these concerns, a subject-centered phased rehabilitation plan of care with goals/ milestones was designed with the subject for advancing rehabilitation and returning to sports at the end of the first visit. Each subsequent stage was connected to the subject's relevant needs as an athlete.

The plan of care was divided into three phases using "chunking" techniques to establish the rehabilitation priorities. ${ }^{34-36}$ Chunking, or grouping information into smaller, easy to remember pieces, was utilized in order to enhance recall of the stages in order to minimize risks of non-compliance. ${ }^{34-36}$ For each stage, the subject and physical therapist each developed 2 to 3 goals that would signal he was 
Table 3: Objective Measures

\begin{tabular}{|l|c|c|}
\hline & Initial Measure & Final Measure (Week 17) \\
\hline PROM $^{(}\left(^{\circ}\right)$ & $3-75$ & $0-135$ \\
\hline AROM $\left.^{(}{ }^{\circ}\right)$ & $8-60$ & $0-135$ \\
\hline Quadriceps tone & Poor, limited activation & No deficit noted \\
\hline MMT Quadriceps & Deferred due to acuity of surgery & $5 / 5$ \\
\hline MMT Hamstrings & Deferred due to acuity of surgery & $5 / 5$ \\
\hline HS length (90/90) & $-50^{\circ}$ & $-10^{\circ}$ \\
\hline Modified Stroke & 3+ & 0 \\
\hline Patellar Mobility & Hypomobile, Pain free & Normal mobility, Pain free \\
\hline Tibiofemoral Mobility & Hypomobile, Painful & Normal mobility, Pain free \\
\hline Quadriceps Symmetry (60 degrees/second) & Not Tested & $80 \%$ \\
\hline Quadriceps Symmetry (300 degrees/second) & Not Tested & $91 \%$ \\
\hline Hamstring Symmetry (60 degrees/second) & Not Tested & $89 \%$ \\
\hline Hamstring Symmetry (300 degrees/second) & Not Tested & $121 \%$ \\
\hline
\end{tabular}

PROM: passive range of motion; AROM: active range of motion; MMT: manual muscle testing; HS: hamstring.

"Range of motion shorthand interpretation. The first number refers to the knee extension value, and the second number refers to the knee flexion value. For a ROM assessment of $3-75$, this can be interpreted as the subject lacking $3^{\circ}$ of knee extension and only yielding $75^{\circ}$ of knee flexion. A reading of 3-0-120 would indicate that the subject has hyperextension of the knee by $3^{\circ}$ and $120^{\circ}$ of flexion.

Table 4: Stages of Rehabilitation and Goals

\begin{tabular}{|c|c|c|}
\hline Stage & Goals & $\begin{array}{l}\text { Therapeutic Alliance } \\
\text { Competencies }\end{array}$ \\
\hline Phase 1: Restore ROM (weeks 0-4) & $\begin{array}{l}\text { 1. Knee ROM } 5^{\circ}-85^{\circ} \text { or greater } \\
\text { 2. O Edema (modified sweep) } \\
\text { 3. Gait with } \leq 5^{\circ} \text { extension lag }\end{array}$ & $\begin{array}{l}\text { 1. Congruence in goals } \\
\text { 2. Communication Style } \\
\text { 3. Partnership in Decision } \\
\text { 4aking } \\
\text { 4. Influencing Factors } \\
\text { 5. Establishing Roles and Re- } \\
\text { sponsibilities }\end{array}$ \\
\hline $\begin{array}{l}\text { Phase 2: Strengthening (weeks } \\
5-10 \text { ) }\end{array}$ & $\begin{array}{l}\text { 1. Knee ROM: } 0^{\circ}-125^{\circ} \text { or greater } \\
\text { 2. Gait: No visual limp } \\
\text { 3. SL leg press } \geq 50 \% \text { of } 1 R M \text { on unaffected limb by week } 6 ; \geq \\
80 \% \text { by week } 8 \\
\text { 4. SL knee extension } \geq 50 \% \text { of } 1 \mathrm{RM} \text { on unaffected limb by } \\
\text { week } 6 ; \geq 80 \% \text { by week } 8\end{array}$ & $\begin{array}{l}\text { 1. Connectedness } \\
\text { 2. Clear Expectations for the } \\
\text { process } \\
\text { 3. Individualized Treatments } \\
\text { to the subject }\end{array}$ \\
\hline $\begin{array}{l}\text { Phase 3: Return to Sport (week } 11 \\
\text { and beyond) }\end{array}$ & $\begin{array}{l}\text { 1. Full tuck position for racing } \\
\text { 2. Jog } \times 5 \text { minutes without pain } \\
\text { 3. Isokinetic Quad symmetry } \geq 80 \% \text { unaffected limb on } \\
\text { electromechanical dynamometer } \\
\text { 4. Return to racing competitively }\end{array}$ & $\begin{array}{l}\text { 1. Partnership in Decision } \\
\text { Making } \\
\text { 2. Accountability for respon- } \\
\text { sibilities } \\
\text { 3. Clear Expectations for the } \\
\text { situation }\end{array}$ \\
\hline
\end{tabular}

ROM: range of motion; SL: single leg; RM: repetition maximum

ready to progress his activity, and selected which goals would be most relevant to use (Table 4). The value of subject input in the development of goals is well documented, and a significant portion of the evaluation was spent developing these goals. ${ }^{1-4,6}$ By improving recall and establishing clear priorities with the collaboration of the subject and his par- ents, therapeutic alliance was enhanced. In order to assess progress, the goals for each stage were measured at the start and finish of each session, and the subject was asked to reflect on his progress after each visit. 


\section{PHYSICAL THERAPY AND THERAPEUTIC ALLIANCE INTERVENTIONS THROUGH THE STAGES}

The criteria for progression through the phases of rehabilitation focused on protection of the surgery and restoration of range of motion within the first four weeks (Figure 2). Once full knee extension $\left(0^{\circ}\right)$ was achieved, knee flexion as within normal limits (approximately $125^{\circ}$ ), and the surgeon was satisfied with bone healing from the surgery, the focus of the rehabilitation plan turned to strengthening. When Phase 2 goals were met, the focus shifted to sports specific exercises and achieving the necessary strength to prevent future injury and enhance performance. A primary measure of this was isokinetic quadriceps symmetry $\geqslant 80 \%$ of the unaffected limb on electromechanical dynamometer (Biodex System III Dynamometer, Biodex Medical Systems, Shirley, NY) testing and performance of sports specific tasks.

\section{PHYSICAL THERAPY PHASE 1: RESTORATION OF RANGE OF MOTION (TABLES $\underline{3} \& \underline{4}$ )}

Phase 1 interventions targeted restoring total knee range of motion to within $75 \%$ of his uninvolved knee, as well as reducing swelling and increasing knee extension during midstance and push off phases of gait cycle. During this stage of rehabilitation, which lasted about four weeks, all eight aspects of building therapeutic alliance (Table 1) were demonstrated. Significant time was spent each session educating the subject and his parents about the severity of the injury, as well as establishing goals for each stage with subject and family feedback were important factors related to his success. During the initial evaluation, the subject's parents expressed concerns about the large number of impairments, including weakness, limited range of motion, swelling, and abnormal gait pattern, and felt overwhelmed by the number of problems he had developed. Acknowledgment of the number of issues, as well as open communication regarding goals of each stage of rehabilitation significantly improved therapeutic alliance with the subject and resulted in a high degree of "buy-in" from the subject and his parents. The number of deficits present and the complications that occurred to date in the case made the end goal of returning to sport seem distant and unattainable. Through goal setting during each phase of the rehabilitation, the calm demeanor of the physical therapist, and shared decision making to make an individualized plan, the subject and his parents felt comfortable that this physical therapist could help the subject obtain his goal of return to sport.

Congruence in goals and expectations were created by having the subject and his father define hydroplane racing as their primary goal, and acknowledging and accepting this as the primary goal for the episode. Limited research guides the prognosis for such a case, the treating physical therapist was open about this, and this honesty in communication helped to establish a connection with both the subject and his family, enhancing the therapeutic alliance. Interventions that build trust, including manual therapy techniques that have been shown to improve range of motion, pain, and

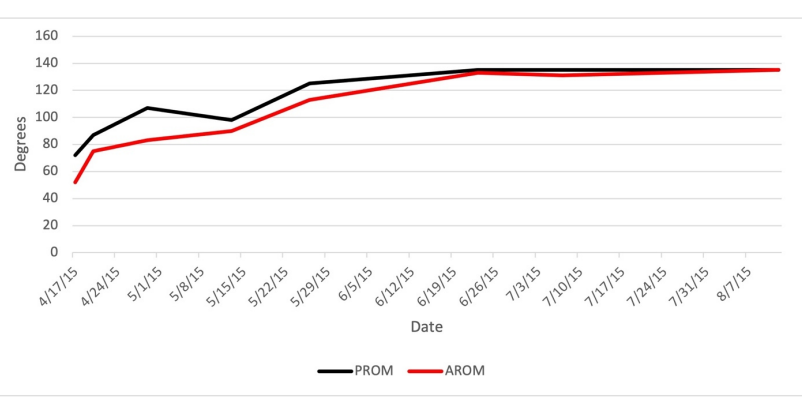

Figure 2: Range of Motion Changes During Physical Therapy

function, as well as build rapport with the subject were included. Manual therapy was used as a staple of therapy at this stage to decrease pain and improve range of motion, which further established therapeutic alliance. ${ }^{14,37-42}$ During therapeutic exercise and manual therapy sessions, the subject provided input on the intensity of the intervention and if it was meeting the goal of increasing range of motion, and treatments were adjusted based on his input. By allowing the subject partnership in the rehabilitation process to help structure the session, it developed communication and clear expectations for the treatment, as he gained trust with the physical therapist the therapeutic alliance appeared to be improved. An example of this occurred when the subject reported that he was fatigued with manually stretching his knee in clinic, and wanted to ride a stationary bicycle to increase range of motion. After educating him about the needed requirements to increase his mobility with seat settings, the subject elected to use the stationary bicycle on a setting that would require additional motion beyond which was measured at the start of the session. He would rock his knee back and forth, self-mobilizing, until he was able to complete a revolution on the bike.

The rapport and trust between the subject and the physical therapist enhanced home exercise adherence during Phase 1 intervention. Although adherence to the home exercise program was self-reported by the subject, the physical therapist created a relationship with the subject that emphasized honesty. Because of the strong rapport and therapeutic alliance developed, the physical therapist felt the self-report of home exercise program adherence was accurate. In addition to his home exercise program, the subject created his own passive range of motion mechanism using a recliner at home. He demonstrated significant commitment to the goal of regaining his range of motion, above and beyond just performing his prescribed home exercise program. This commitment helped to maintain an orderly progression in the early stages of rehabilitation, and established a foundation of trust for future stages.

\section{PHASE 2: STRENGTHENING THERAPEUTIC ALLIANCE \& INCREASING FUNCTIONAL MOBILITY (TABLE 4)}

Phase 2 interventions targeted increasing strength of the quadriceps, hamstrings, and translating these strength gains into functional mobility needed for sports participation. Interventions from the previous stage were phased 
out, and replaced with resisted active range of motion and weight bearing exercises. At the start of this phase of rehabilitation, most bilateral activities resulted in a large weight shift, assessed visually, onto the uninvolved limb. ${ }^{43}$ In order to address excessive weight-shifting onto the uninvolved limb, exercises were performed in front of a mirror for visual feedback, and verbal and tactile cues were given to enhance feedback and improve loading/shifting weight on the right knee. The physical therapist engaged the subject by providing verbal cues requiring the subject to interact, including asking the subject if he felt his loading was equal on the left and right limb and self-grading of his movements after completion. While performing the exercises, the subject was asked how he thought the repetition went, and what he would recommend to change the movement. When he was unsure how to address what he saw, the physical therapist provided cueing to assist in changing the exercise, but emphasis was placed on the subject providing feedback to the physical therapist. This helped to establish the subject as a valued contributor to the sessions, and further strengthened the therapeutic alliance. Key aspects of the therapeutic alliance that were built and reinforced during this stage included clear communication, building of connection between the physical therapist and the subject, individualized treatments based on subject needs, and shared decision making on when to adjust interventions.

At the end of this stage, the subject expressed frustration that his strength was not progressing fast enough. Strength gains in Phase 2 prior to isokinetic testing are highlighted in Figure 3. He verbalized that he had low motivation to perform home exercises, and self-progressed to jogging. The return to jogging criteria had not been met and the subject had not been cleared by the physical therapist to jog. A limb symmetry index of $80 \%$ is recommended before attempting to jog. ${ }^{44}$ To manage this frustration, the subject and physical therapist agreed that he would begin performing sport-like motions for hydroplane racing, and would be allowed to jog in the clinic as long as he did not advance his activity level on his own at school. This was a compromise made by the physical therapist to gain control of what the subject was doing for his home exercise program. Through shared decision making the subject and physical therapist compromised on only running in clinic in a controlled environment and not outside on his own. Risks of progressing too early into sports, including re-fracture of the femur, iatrogenic injury to other joints due to poor strength, and potential long-term changes to movement patterns due to maladaptive loading were explained to the subject and his parents. The parents and subject understood these concerns, and the parents provided consent to progress into higher level activities. Although adequate healing should have occurred by this point, a methodical conservative progression was advised for an optimal outcome and prevent any relapses or exacerbation of pain. Without establishing a strong therapeutic alliance, it is likely that the subject may have had a suboptimal outcome due to self-progression. However, the subject admitting and expressing this frustration was facilitated directly from the trust he had built with the physical therapist.

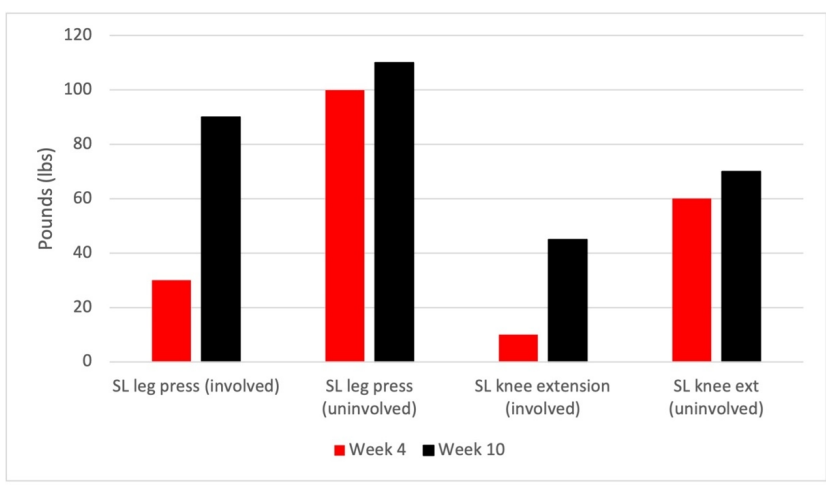

Figure 3: Changes in Single Leg Strength during Phase 2

\section{PHASE 3: THERAPEUTIC ALLIANCE AND RETURN TO SPORT (TABLE 4)}

During the final stage of rehabilitation, the subject began sport specific training aimed at returning to hydroplane racing. This stage provided an excellent opportunity for therapeutic alliance by creating partnership in decision making, building and establishing new roles and responsibilities, and using the rehabilitation environment to enhance the rehabilitation process. The subject reported that he would prefer to work on hydroplane racing as much as possible during this stage, as his national competition was approaching. In order to better understand the demands of hydroplane racing, pictures of equipment were brought into the clinic and video analysis of the subject's previous races were led by the subject and his father. This instruction helped the subject and his father feel heard, and helped the physical therapist understand the demands of the sport (Table 2). They focused on specific maneuvers to steer the boat, as well as emergency evasive maneuvers and procedures when crashes occurred and the racer was ejected from the boat. In these meetings, the subject led the meeting providing insight into the sport, and this cemented the rapport developed with the subject across the plan of care, and minimized any fear-avoidance beliefs from both the subject and his family. By better understanding the sport, the physical therapist was able to target interventions that helped the subject and his parents develop confidence in his ability to safely return to sport. The subject was able to feel comfortable knowing that the physical therapist understood his sport, as he had taught the physical therapist how racing worked. The subject and his father changed their roles, and became leaders of the rehabilitation team by providing instruction on racing. They were able to help create safe return to activity criteria, and then provided video analysis of the subject performing practice runs to more specifically target interventions as the stage came to a close. This relationship helped set the stage for a safe return to competition, and the authors feel that the therapeutic alliance was central to his return to competition.

This stage also utilized the rehabilitation environment to help build confidence. In order to safely evaluate if the subject could handle steering the boat, rehabilitation equipment was modified and used to create a dynamic surface 
that the subject could "ride" and "steer" by manipulating his body weight. Early interventions challenged the subject to return to the crouched position required to sit in the cock pit of his boat on the ground. A graded-exposure approach to intervention selection was taken to challenge balance, strength, reduce fear, and boost confidence. The interventions started with a static tuck on a solid surface, and as he gained confidence, the subject was challenged to perform weight shifting and upper extremity motions such as rowing and shoulder extension while in a tuck. This replicated an unstable surface similar to what he dealt with while racing over water, and he progressed from static holds to weight shifting and reaching while on the BOSU (Figure 4). By modifying equipment in the environment, the therapeutic alliance was once again enhanced, and helped to build confidence that when he completed the rehabilitation process he would be safe to boat again.

\section{DESCRIPTION OF OUTCOMES}

The episode of care spanned 17 weeks and included 25 physical therapy sessions. Objective data and subject reported outcomes are listed in Table 3 . The subject demonstrated substantially improved knee range of motion, and was able to comfortably sit in the crouched position required for hydroplane racing. Strength of the quadriceps and hamstrings also improved, with the lowest symmetry identified in force production of the quadriceps at $60^{\circ} / \mathrm{sec}-$ ond during isokinetic testing (Table 3). These speeds were extrapolated from ACL reconstruction guidelines and return to sport criteria. ${ }^{44-46} \mathrm{He}$ was cleared by the surgical team to return to full activity, and encouraged to continue with his home exercise program. The subject was able to return to hydroplane racing without impairments and minimal compensations in gear and boat set up, and won a national championship in his age group. Subject reported outcomes were not collected at the end of episode of care, as the subject missed his discharge appointment due to illness.

\section{SUBJECT PERSPECTIVE AND POST-PHYSICAL THERAPY FOLLOW UP}

The physical therapist contacted the subject through electronic mail (e-mail) five years from his last visit after the surgery to get an update and to have him fill out various subject reported outcome measures regarding general health, knee function, fear of movement and therapeutic alliance. The subject responded with the following message:

"Lacrosse and racing the past couple years has been so much fun and I couldn't thank you enough because you were a part of my journey to getting back on track. I play lacrosse now at [removed for subject privacy] University and I actually played in all six games this year. I also led all freshmen in ground balls and third overall on the team for groundballs... Being a part of that lacrosse team has been a blessing, the people I have met are so kind, but have also pushed me to become a better person and student.

Racing has been another blessing in my life. I have met so many people and learned so many great life lessons

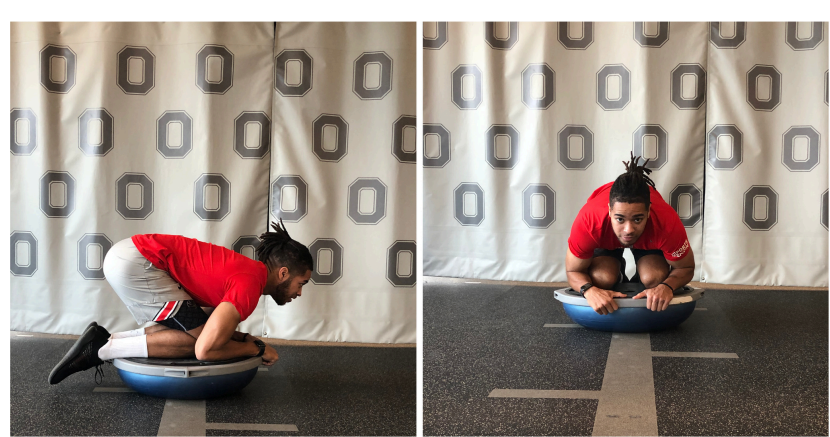

\section{Figure 4: Sports specific exercise for hydroplane} racing

The interventions started with a static tuck on a solid surface, and as he gained confidence, the patient was challenged to perform weight shifting and upper extremity motions such as rowing and shoulder extension while in a tuck. This replicated an unstable surface similar to what he dealt with while racing over water, and he progressed from static holds to weight shifting and reaching while on the BOSU. By modifying equipment in the environment, the therapeutic alliance was once again enhanced, and helped to build confidence that when he completed the rehabilitation process he would be safe to boat again.

from it! You helped me return to that racing season in the summer of 2015 to win my first national championship. Now the crazy part here is after that I have gone on to win six more national championships and have received three hall of champions inductions. Honestly, boat racing would not have been the same without my treatment from OSU and you."

Although the emphasis of this case is on therapeutic alliance there was no formal evaluation of this during the subject's time with the physical therapist, so the subject and physical therapist completed a survey regarding therapeutic alliance retroactively. The Working Alliance Inventory (WAI) measures three domains of therapeutic alliance: 1) agreement between therapist and subject regarding goals of a given treatment, 2) agreement between therapist and subject regarding tasks to achieve set goals, 3) Quality of bond between therapist and subject. ${ }^{47}$ The subject scored a total WAI score of 70 (Goal items: 21, Task items: 21, Bond items: 28). The physical therapist scored a total WAI score of 69 (Goal items: 22, Task items: 21, Bond items: 26). The similarity in scores between the subject and physical therapist suggest high therapeutic alliance between them.

The subject also completed the Lower Extremity Functional Scale (LEFS), the Fear Avoidance Believe Questionnaire (FABQ), and the Tampa Scale of Kinesiophobia (TSK). He scored an 80 out of 80 on the LEFS suggesting full lower extremity function. He demonstrated low fear with scores on FABQ physical activity scale on of 5 and work subscale of 0 , and low fear of movement on the TSK with a score of 29.

\section{DISCUSSION}

Within care for musculoskeletal conditions, therapeutic alliance has been identified as an area of emphasis for research and understanding due to the potential link between therapeutic alliance and adherence. ${ }^{48,49}$ Outside of musculoskeletal conditions, therapeutic alliance has been used to enhance commitment to behavioral change. These changes 
have been studied in medicine and psychology, and demonstrate that therapeutic alliance enhances outcomes in chronic disease care, and enhances adherence to treatment recommendations. It has been linked to improved quality of life, subject satisfaction, and psychological well-being. ${ }^{7}$ When working with medical specialists, subjects felt that the specialist being present in the moment, allowing them to feel like they were "seen, heard, and believed" was a crucial aspect to improving the subject's perception of the quality of the interaction. Research in spinal conditions and chronic pain, where it is common to treat subjects with abnormal presentations and treatment is recommended by broad guidelines, developing therapeutic alliance is likely to enhance adherence and improve subject outcomes. ${ }^{9,11}$ In cases where limited research or evidence exists to guide clinical decision making the development of a strong therapeutic alliance is necessary to manage unexpected outcomes and information, and thus enhance clinical outcomes.

The unique aspect of this case was the incorporation of therapeutic alliance concepts and techniques into the complicated rehabilitative management of a fracture of the distal femoral epiphysis. The authors feel that the incorporation of these concepts was imperative for the successful outcome. In complicated cases, it is easy to be overwhelmed by the number of impairments present and inefficiently allocate time to all impairments rather than prioritize the impairments. This approach may limit therapeutic alliance and rapport and may ultimately result in suboptimal outcomes due to being "spread too thin". 2,6 Rather than focus on the large number of impairments and initiating treatment as rapidly as possible, a substantial amount of time during the first appointment was dedicated, by design, to communication and creating trust. Further, the therapist focused on a limited number of impairments in each stage of rehabilitation, and frequently related interventions back to the overall goal of the stage. Compliance and subject engagement with the rehabilitation plan was established early on, and was important to maintaining focus on select impairments across the episode of care. Further, it appeared to the treating physical therapist that it enhanced therapeutic alliance with the subject, which has been shown to improve compliance with instructions and outcomes in rehabilitation. ${ }^{1-4,6}$

In this case, therapeutic alliance techniques were used to facilitate education and communication with the subject, improve exercise/activity compliance, enhance exercise interventions, and augment other techniques focused on restoring and return to high levels of activity. This may shorten the overall episode of care and improve clinical decision making for progression of activity and identification of needs for early referral back to other medical disciplines. Therapeutic alliance has been shown to improve motivation and outcomes in chronic low back pain, as well as improving adherence to home exercise programs. ${ }^{9-11}$ In this case, the subject provided feedback on interventions in the early stages, contributing directly to evaluating the interventions addressing his limitations. In the later stages of rehabilitation, the subject provided the therapist with substantial input and feedback to create relevant interventions that would have been missed without an intimate understand- ing of his sport. Even when he attempted to self-progress back to sports before meeting the therapeutic goals, the established therapeutic alliance allowed for an open conversation and the therapist and the subject were able to reach a compromise that maintained his safety and helped him continue to progress. Without a strong therapeutic alliance, these conversations may result in non-compliance with recommended interventions and possible subject injury due to inappropriate progression. ${ }^{10}$

\section{LIMITATIONS AND FUTURE RESEARCH}

This case report has several limitations. Case reports represent a low form of evidence to inform clinical decision making, and further research is needed to validate the concepts discussed in this case. Also, cause and effect cannot be determined in this case report, and it is possible he could have improved with time from the surgery and without intervention. Although research on the value of therapeutic alliance is prominent in other areas of health care, physical therapy research is limited. Further, limited data exists for appropriate timing of progression of interventions following repair of epiphyseal fractures. Although inventories exist to measure therapeutic alliance, none were utilized as part of the standard care provided at the treating facility and was not objectively quantified until five years after the last visit. Future case reports and research studies should consider valid and reliable forms of therapeutic alliance measurement such as the WAI throughout the plan of care ${ }^{47,50}$ Although the case demonstrates the physical therapist and subject accomplished all three of the aforementioned domains, the case report would have been strengthened with an objective measurement of therapeutic alliance throughout the plan of care, rather than retroactively obtaining these measures. ${ }^{47,50}$

The authors suggest that measuring therapeutic alliance would be a useful adjunct to clinical care in complicated and chronic cases, and cases where progression is limited, as it may provide insights into factors that may contribute to slow progression. This case provides guidance for the sequencing of interventions specific to injuries of the distal femoral epiphysis, but to the authors' knowledge, there is not a specific sequence of events to build therapeutic alliance, and so the authors encourage clinicians to use this as a guideline rather than an absolute series of steps.

\section{CONCLUSION}

Therapeutic alliance may be used to improve subject outcomes and enhance care provided for musculoskeletal conditions. The authors feel that using therapeutic alliance concepts enhanced communication and rapport with the subject and limited his frustration and pre-emptive attempts to self-progress too quickly for his physical state. Factors related to success in this case included initial "buyin" of the subject and his family to the rehabilitation plan through their direct input in creating measurable goals to progress through the stages of his rehabilitation. Clinicians should be mindful of therapeutic alliance during the initial evaluation, and therapeutic alliance should continue to be 
built across the episode of care. It is recommended that clinicians utilize similar techniques to assist in the management of complicated cases and help guide decision making when limited literature exists on injuries such as the one described in this case.

\section{CONFLICTS OF INTEREST}

Authors have no financial disclosures or conflicts of interest related to this project.

Submitted: October 07, 2019 CDT, Accepted: October 10, 2020 CDT 


\section{REFERENCES}

1. Leach M. Rapport: A key to treatment success. Complement Ther Clin Pract. 2005;4:262-265. doi:10.1 016/j.ctcp.2005.05.005

2. Vahdat S, Hamzehgardeshi L, Hessam S, Hamzehgardeshi Z. Subject involvement in health care decision making: A review. Iran Red Crescent Med J. 2014;16(1):1-7. doi:10.5812/ircmj.12454

3. Nissen-lie HA, Havik OE, Høglend PA, Rønnestad $\mathrm{MH}$, Monsen JT. Subject and therapist perspectives on alliance development: Therapists ' practice experiences as predictors. Clin Psychol Psychother. 2015;327(February 2014):317-327. doi:10.1002/cpp.18 $\underline{91}$

4. Elvins R, Green J. The conceptualization and measurement of therapeutic alliance: An empirical review. Clin Psychol Psychother. 2008;28:1167-1187. $\underline{\mathrm{d}}$ oi:10.1016/i.cpr.2008.04.002

5. O’Keeffe M, Cullinane P, Hurley J, et al. What influences subject-therapist interactions in musculoskeletal physical therapy? Qualitative systematic review and meta-synthesis. Phys Ther. 2016;96(5):609-622. doi:10.2522/ptj.20150240

6. Ackerman SJ, Hilsenroth MJ. A review of therapist characteristics and techniques positively impacting the therapeutic alliance. Clin Psychol Rev. 2003;23:1-33. doi:10.1016/S0272-7358(02)00146-0

7. Babatunde F, MacDermid J, MacIntyre N Characteristics of therapeutic alliance in musculoskeletal physiotherapy and occupational therapy practice: a scoping review of the literature. BMC Health Serv Res. 2017;17(1):375. doi:10.1186/s12 913-017-2311-3

8. Moore CL, Kaplan SL. A framework and resources for shared decision making: Opportunities for improved physical therapy outcomes. Phys Ther. 2018;98(12):1022-1036. doi:10.1093/ptj/pzy095

9. Vong SK, Cheing GL, Chan F, So EM, Chan CC. Motivational enhancement therapy in addition to physical therapy improves motivational factors and treatment outcomes in people with low back pain: A randomized controlled trial. Arch Phys Med Rehabil. 2011;92(2):176-183. doi:10.1016/i.apmr.2010.10.016

10. Wright B, Galtieri N, Fell M. Non-adherence to prescribed home rehabilitation exercises for musculoskeletal injuries: The role of the patientpractitioner relationship. J Rehabil Med. 2014;46(2):153-158. doi:10.2340/16501977-1241
11. Fuentes J, Armijo-Olivo S, Funabashi M, et al. Enhanced therapeutic alliance modulates pain intensity and muscle pain sensitivity in subjects with chronic low back pain: An experimental controlled study. Phys Ther. 2014;94(4):477-489. doi:10.2522/pt j.20130118

12. Arkader A, Warner WC, Horn BD, Shaw RN, Wells L. Predicting the outcome of physeal fractures of the distal femur. J Pediatr Orthop. 2007;27(6):703-708. do i:10.1097/BPO.0b013e3180dca0e5

13. Gulabi D, Erdem M, Bulut G, Avci CC, Asci M. Ipsilateral distal femoral and proximal tibial epiphyseal growth plate injury: a case report. J Med Case Rep. 2013;7(1):146. doi:10.1186/1752-1947-7-14 $\underline{6}$

14. Millett PJ, Johnson B, Carlson J, Krishnan S, Steadman JR. Rehabilitation of the arthrofibrotic knee. Am J Orthop. 2003;32(11):531-538.

15. Moran M, Macnicol MF. (ii) Paediatric epiphyseal fractures around the knee. Curr Orthop. 2006;20(4):256-265. doi:10.1016/J.CUOR.2006.03.002

16. Sabharwal S, Sabharwal S. Growth plate injuries of the lower extremity: Case examples and lessons learned. Indian J Orthop. 2018;52(5):462. doi:10.4103/ ORTHO.IJORTHO 31317

17. Yenchak AJ, Wilk KE, Arrigo CA, Simpson CD, Andrews JR. Criteria-based management of an acute multistructure knee injury in a professional football player: A case report. J Orthop Sport Phys Ther. 2011;41(9):675-686. doi:10.2519/jospt.2011.3453

18. Sprague RB. Factors related to extension lag at the knee joint. J Orthop Sports Phys Ther. 1982;3(4):178-182. doi:10.2519/jospt.1982.3.4.178

19. Willy RW, Hoglund LT, Barton CJ, et al. Patellofemoral Pain. J Orthop Sports Phys Ther. 2019;49(9):CPG1-CPG95. doi:10.2519/jospt.2019.030 $\underline{2}$

20. Arundale AJH, Bizzini M, Giordano A, et al. Exercise-based knee and anterior cruciate ligament injury prevention. J Orthop Sports Phys Ther. 2018;48(9):A1-A42. doi:10.2519/jospt.2018.0303

21. Logerstedt DS, Scalzitti D, Risberg MA, et al. Knee stability and movement coordination impairments: Knee ligament sprain revision 2017. J Orthop Sports Phys Ther. 2017;47(11):A1-A47. doi:10.2519/jospt.201 7.0303 
22. Berríos-Torres SI, Umscheid CA, Bratzler DW, et al. Centers for Disease Control and Prevention Guideline for the prevention of surgical site infection, 2017. JAMA Surg. 2017;152(8):784. doi:10.1001/jamas urg.2017.0904

23. Basson A, Olivier B, Ellis R, Coppieters M, Stewart A, Mudzi W. The effectiveness of neural mobilization for neuromusculoskeletal conditions: A Systematic review and meta-analysis. J Orthop Sports Phys Ther. 2017;47(9):593-615. doi:10.2519/jospt.2017.7117

24. Butler D. The sensitive nervous system. NOIgroup Publication, Adelaide, Australia, 2000.

25. Mansfield CI, Bleacher J, Tadak P, Briggs MS. Differential examination, diagnosis and management for tingling in toes: Fellow's case problem. J Man Manip Ther. 2016. doi:10.1080/10669817.2016.126067 $\underline{5}$

26. Sturgill LP, Snyder-Mackler L, Manal TJ, Axe MJ. Interrater reliability of a clinical scale to assess knee joint effusion. J Orthop Sports Phys Ther. 2009;39(12):845-849. doi:10.2519/jospt.2009.3143

27. Sturgill LP, Snyder-Mackler L, Manal TJ, Axe MJ. Interrater reliability of a clinical scale to assess knee joint effusion. J Orthop Sports Phys Ther. 2009;39(12):845-849. doi:10.2519/jospt.2009.3143

28. Kendall FP, Kendall FP. Muscles: Testing and Function with Posture and Pain. Lippincott Williams \& Wilkins; 2005.

29. Rothstein JM, Miller PJ, Roettger RF. Goniometric reliability in a clinical setting. Phys Ther. 1983;63(10):1611-1615. doi:10.1093/ptj/63.10.1611

30. Reiman MP, Manske RC. Functional Testing in Human Performance. Human Kinetics; 2009.

31. Levene JA, Hart BA, Seeds RH, Fuhrman GA. Reliability of reciprocal isokinetic testing of the knee extensors and flexors. J Orthop Sports Phys Ther. 1991;14(3):121-127. doi:10.2519/jospt.1991.14.3.121

32. Reynolds JM, Gordon TJ, Robergs RA. Prediction of one repetition maximum strength from multiple repetition maximum testing and antrhopometry. J Strength Condit Res. 2006;20(3):584-592.

33. Sinacore JA, Evans AM, Lynch BN, Joreitz RE, Irrgang JJ, Lynch AD. Diagnostic accuracy of handheld dynamometry and 1-repetition-maximum tests for identifying meaningful quadriceps strength asymmetries. J Orthop Sports Phys Ther. 2017;47(2):97-107. doi:10.2519/jospt.2017.6651
34. Chekaf M, Cowan N, Mathy F. Chunk formation in immediate memory and how it relates to data compression. Cognition. 2016;155:96-107. doi:10.101 6/j.cognition.2016.05.024

35. Solopchuk O, Alamia A, Olivier E, Ze A. Chunking improves symbolic sequence processing and relies on working memory gating mechanisms. Learn Mem. 2016:108-112.

36. Fonollosa J, Neftci E, Rabinovich M. Learning of chunking sequences in cognition and behavior. PLoS Comput Biol. 2015:1-24. doi:10.1371/journal.pcbi.100 $\underline{4592}$

37. Courtney CA, Steffen AD, Fernández-de-las-peñas C, Kim J, Chmell DPTSJ. Joint mobilization enhances mechanisms of conditioned pain modulation in individuals with osteoarthritis of the knee. J Orthop Sports Phys Ther. 2016;46(3):168-176. doi:10.2519/jos pt.2016.6259

38. Winslow J. Treatment of lateral knee pain using soft tissue mobilization in four female triathletes. Int J Ther Massage Bodyw. 2014:25-31.

39. Noten S, Meeus M, Stassijns G, Glabbeek F, Verborgt O, Struyf F. Efficacy of different types of mobilization techniques in subjects with primary adhesive capsulitis of the shoulder: A systematic review. Arch Phys Med Rehabil. 2016;97(5):815-825. oi:10.1016/j.apmr.2015.07.025

40. Landrum EL, Kelln BM, Parente WR, Ingersoll CD, Hertel J. Immediate effects of anterior-to-posterior talocrural joint mobilization after prolonged ankle immobilization: A preliminary study. J Man Manip Ther. 2008;16(2):100-105. doi:10.1179/106698108790 $\underline{818413}$

41. Takasaki H, Hall T, Jull G. Immediate and shortterm effects of Mulligan's mobilization with movement on knee pain and disability associated with knee osteoarthritis - A prospective case series. Physiother Theory Pract. 2013;29(2):87-95. doi:10.310 9/09593985.2012.702854

42. Silva RD, Teixeira M, Santos T, Teixeira-salmela LF, Resende MA. Effects of anteroposterior talus mobilization on range of motion, pain, and functional capacity in participants with subacute and chronic ankle injuries: A controlled trial. $J$ Manipulative Physiol Ther. 2017;40(4):273-283. doi:1 0.1016/j.jmpt.2017.02.003

43. Sigward SM, Chan M-SM, Lin PE, Almansouri SY, Pratt KA. Compensatory strategies that reduce knee extensor demand during a bilateral squat change from 3 to 5 months following anterior cruciate ligament reconstruction. J Orthop Sports Phys Ther. 2018;48(9):713-718. doi:10.2519/jospt.2018.7977 
44. Adams D, Logerstedt DS, Hunter-Giordano A, Axe MJ, Snyder-Mackler L. Current concepts for anterior cruciate ligament reconstruction: a criterion-based rehabilitation progression. J Orthop Sports Phys Ther. 2012;42(7):601-614. doi:10.2519/jospt.2012.3871

45. Schmitt LC, Paterno M, Hewett TE. The impact of quadriceps femoris strength asymmetry on functional performance at return to sport following anterior cruciate ligament reconstruction. J Orthop Sports Phys Ther. 2012;42(9):750-759. doi:10.2519/jospt.2012.419 $\underline{4}$

46. Myer GD, Paterno M, Ford KR, Quatman CE, Hewett TE. Rehabilitation after anterior cruciate ligament reconstruction: Criteria-based progression through the return-to-sport phase. J Orthop Sports Phys Ther. 2006;36(6):385-402. doi:10.2519/jospt.200 $\underline{6.2222}$
47. Paap D, Dijkstra PU. Working alliance inventoryshort form revised. J Physiother. 2017;63(2):118. doi:1 0.1016/i.jphys.2017.01.001

48. Foster NE, Dziedzic KS, Windt DA, Fritz JM, Hay EM. Research priorities for non-pharmacological therapies for common musculoskeletal problems: nationally and internationally agreed recommendations. BMC Musculoskelet Disord. 2009;10(1):3. doi:10.1186/1471-2474-10-3

49. Rankin G, Rushton A, Olver P, Moore A. Chartered Society of Physiotherapy's identification of national research priorities for physiotherapy using a modified Delphi technique. Physiotherapy. 2012;98(3):260-272. doi:10.1016/i.physio.2012.03.002

50. Hatcher RL, Gillaspy JA. Development and validation of a revised short version of the working aliance inventory. Psychother Res. 2006;16(1):12-25. d oi:10.1080/10503300500352500 